\title{
Research on the Scale Coordinated Development Mode of Chinese Undergraduate Universities
}

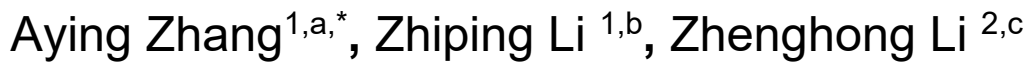 \\ ${ }^{1}$ Harbin University, 150086 Harbin, China \\ ${ }^{2}$ Harbin Institute of Technology, 150001 Harbin, China \\ a,*zaying@sina.com, blizp2008@126.com, c273662999@qq.com
}

Keywords: Coordinated development, Mode, Undergraduate, Universities.

\begin{abstract}
The scale coordination model of undergraduate university development is: in the initial stage of the establishment of undergraduate university, the scale of each juxtaposed factor (student factor, teacher factor, condition factor, management factor, cultural factor) is developing quantitatively, while the various factors meet the quality requirements and coordinated development process and results among them. In other words, the coordinated development of the juxtaposed elements in the initial stage of the establishment of an undergraduate university is the regular path of its connotation development. With a contingent of teachers with reasonable structure, appropriate scale and higher teaching level, with teachers-centered in teaching and students-centered in educating, and with policies conducive to the construction of the contingent of teachers and academic activities, with a good teaching style, style of study and even style of study, all undergraduate universities should be in parallel. Only in the process of the development of each factor scale and the coordinated development of each factor scale can the undergraduate universities improve the quality of education and the efficiency of running schools.
\end{abstract}

\section{Classification of Chinese university's juxtaposition factors}

In order to realize the function of talent cultivation, undergraduate universities must first have students receive education, which is the first element of undergraduate universities: student elements. Secondly, in order to train students, undergraduate universities should be equipped with teachers, which constitutes the second element of undergraduate universities: the elements of teachers. With students and teachers, undergraduate universities should also provide students with teaching rooms, teaching equipment, books and other materials to meet the standards of running a school. These basic construction contents constitute the third element of undergraduate universities: the condition elements. With students, school conditions and teaching staff, undergraduate universities should have managers and presidents. They have established academic system, personnel system and distribution system within the framework of laws and regulations. These constitute the fourth element of undergraduate universities: management elements. In the course of running a university, it is inevitable for the undergraduate university to form academic tradition, teaching style and study style, which constitute the fifth element of the undergraduate university: cultural elements. These five elements are the five important aspects of the development of undergraduate universities, and also the five important contents of academic research.

\section{Quantitative analysis of the relationship between the level of running a university and its coordinating factors in China}

\subsection{Analytical purposes, data acquisition and analysis methods}

\subsubsection{Analytical purposes}

To establish the relationship between the evaluation level of the Ministry of Education and its five internal factors, that is, to quantitatively analyze the influence of five juxtaposed factors, such as 
students, teachers, conditions, management and culture, on the level of running Chinese undergraduate universities.

\subsubsection{Data acquisition}

According to the results of the undergraduate teaching evaluation of China's undergraduate universities published by the Ministry of Education, the five indicators of the evaluation of the Ministry of Education are taken as five elements, and the relevant data are obtained through telephone communication with 99 Chinese undergraduate universities.

\subsubsection{Analytical methods}

Using the method of surface regression analysis in modern statistics for data analysis, using statistical software SAS 8.0 for model fitting, the results are presented intuitively in the form of Tables 1 .

Table 1. The corresponding table of the overall evaluation level and the parallel factor grade of 99 newly established universities.

\begin{tabular}{ccccccc}
\hline School quantity & Students & Teachers & Conditions & Managements & Cultures & Evaluate \\
\hline 6 & A & B & B & A & A & B \\
\hline 4 & A & B & A & B & A & B \\
\hline $\mathbf{2}$ & B & A & A & B & A & B \\
\hline 2 & B & B & A & A & A & B \\
\hline 2 & A & A & B & B & A & B \\
\hline 2 & B & A & B & A & A & B \\
\hline 21 & A & C & B & A & A & C \\
\hline 9 & B & C & A & A & A & C \\
\hline 6 & A & C & A & A & B & C \\
\hline 15 & A & C & A & B & A & C \\
\hline 14 & A & B & C & A & A & C \\
\hline 7 & A & B & A & C & A & C \\
\hline 6 & C & B & A & A & A & C \\
\hline 3 & A & B & A & A & C & C \\
\hline
\end{tabular}

\subsection{Regression analysis process}

\subsubsection{Two response surface equation}

For the convenience of calculation, we assign three grades A, B, C to the score. A is set as 90, B is set as $75, \mathrm{C}$ is set as 60 . At the same time, $\mathrm{y}$ is set as evaluation, $\mathrm{x} 1$ is set as student factor, $\mathrm{x} 2$ is set as teacher factor, $\mathrm{x} 3$ is set as condition factor, $\mathrm{x} 4$ is set as management factor, $\mathrm{x} 5$ is set as cultural factor.

Considering the actual running process, there is interaction among the five parallelism factors such as $\mathrm{x} 1 \ldots . . . \mathrm{x} 5$. Therefore, we establish a surface regression between $\mathrm{y}$ and $\mathrm{xi}$, and make the fitting quadratic response surface equation is shown as equation (1).

$$
\hat{y}=b_{0}+\sum_{i} b_{i} x_{i}+\sum_{i<j} b_{i j} x_{i} x_{j}+\sum_{i} b_{i i} x_{i}^{2}
$$

The task is to determine the regression coefficient $b_{\mathrm{i}}, \mathrm{b}_{\mathrm{i},}, \mathrm{i}, \mathrm{j}=1 \cdots 5$.

\subsubsection{Finding out the relational function model}

Input the data in Table 1 to the Excel form, and take the data of 94 institutions for regression analysis. Here we use the statistical analysis software SAS 8.0 to analyze the data set, select the variable "forward" in the regression process, omit the variable that has no significant effect on $y$, select the variable that has significant effect on $y$, and finally get the fitting model after 0.2 second operation time.

$$
\hat{\mathrm{y}}=-176.43787+1.36774 \mathrm{x}_{2}-0.00274 \mathrm{x}_{2}^{2}+0.01108 \mathrm{x}_{1} \mathrm{x}_{3}+0.01104 \mathrm{x}_{4} \mathrm{x}_{5}
$$

\subsubsection{The process of regression analysis can refer to the SAS output table below}




\begin{tabular}{l}
\hline $\mathrm{y}=\mathrm{x} 2 \times 2 \times 2 \times 1 \times 3 \quad \times 4 \times 5$ \\
Response Dist ribution: Normal \\
\hline Link Function: $\quad$ Identity \\
\hline
\end{tabular}

\begin{aligned} & \hline \\ &$y=-176.438+1.3677 \times 2-0.0027 \times 2 \times 2+0.0111 \times 1 \times 3 \\ &+-0.0110 \times 4 \times 5\end{aligned}$

\begin{tabular}{|c|c|c|c|}
\hline 1 & Sumuary of & Fit & \\
\hline Mean of Response & 62.5532 & $\mathrm{R}$-Square & 0.9980 \\
\hline Root MSE & 0.2612 & $\mathrm{Adj} \mathrm{R}-\mathrm{Sq}$ & 0.9979 \\
\hline
\end{tabular}

\begin{tabular}{|c|c|c|c|c|c|}
\hline \multicolumn{6}{|c|}{ Analysis of Variance } \\
\hline Source & $\mathrm{DF}$ & Sum of Squares & Mean Square & F Stat & $\operatorname{Pr}>\mathrm{F}$ \\
\hline $\begin{array}{l}\text { Model } \\
\text { Error } \\
\text { C Total }\end{array}$ & $\begin{array}{r}4 \\
89 \\
93\end{array}$ & $\begin{array}{r}2981.1638 \\
6.0703 \\
2987.2340\end{array}$ & $\begin{array}{r}745.2909 \\
0.0682\end{array}$ & 10927.17 & $<.0001$ \\
\hline
\end{tabular}

\begin{tabular}{|c|c|c|c|c|c|}
\hline \multicolumn{6}{|c|}{ Type III Tests } \\
\hline Source & DF & Sum of Squares & Mean Square & F Stat & $\mathrm{Pr}>\mathrm{F}$ \\
\hline $\begin{array}{l}x 2 \\
x 2 \times 2 \\
x 1 \times 3 \\
x 4 \times 5\end{array}$ & $\begin{array}{l}1 \\
1 \\
1 \\
1\end{array}$ & $\begin{array}{r}45.9258 \\
3.8085 \\
1848.7850 \\
1617.5101\end{array}$ & $\begin{array}{r}45.9258 \\
3.8085 \\
1848.7850 \\
1617.5101\end{array}$ & $\begin{array}{r}673.35 \\
55.84 \\
27106.18 \\
23715.32\end{array}$ & $\begin{array}{l}<.0001 \\
<.0001 \\
<.0001 \\
<.0001\end{array}$ \\
\hline
\end{tabular}

\begin{tabular}{|c|c|c|c|c|c|c|c|}
\hline \multicolumn{8}{|c|}{ Parameter Estimates } \\
\hline Variable & DF & Estimate & Std Error & t Stat & $\operatorname{Pr}>|t|$ & Tolerance & Var Inflation \\
\hline $\begin{array}{l}\text { Intercept } \\
x 2 \\
x 2 \times 2 \\
x 1 \times 3 \\
x 4 \times 5\end{array}$ & $\begin{array}{l}1 \\
1 \\
1 \\
1 \\
1\end{array}$ & $\begin{array}{r}-176.4379 \\
1.3677 \\
-0.0027 \\
0.0111 \\
0.0110\end{array}$ & $\begin{array}{r}2.4097 \\
0.0527 \\
0.0004 \\
6.732 \mathrm{E}-05 \\
7.166 \mathrm{E}-05\end{array}$ & $\begin{array}{r}-73.22 \\
25.95 \\
-7.47 \\
164.64 \\
154.00\end{array}$ & $\begin{array}{l}<.0001 \\
<.0001 \\
<.0001 \\
<.0001 \\
<.0001\end{array}$ & & $\begin{array}{r}0 \\
288.6997 \\
277.3333 \\
6.3283 \\
5.0929\end{array}$ \\
\hline
\end{tabular}

Fig. 1. The regression analysis process

\subsection{Model verification}

By substituting the data of the other five colleges and universities (the data in bold) into the relational function model equation (2), we can get the total forecast evaluation y of the five schools: 73.77473, 73.77473, 60.09413, 60.09413, 60.09413, 60.09413, and then converted into B, B, C, C, and C, the results are completely consistent with the actual situation. Figure 2 shows that the relationship function model between the running level of Chinese undergraduate universities and the 5 juxtaposition elements is more accurate.

\subsection{Model explanation}

Some results can be seen from the relational function model equation (2). The relationship between the level of school running and the factor of teachers $\mathrm{x} 2$ is quadratic function increasing, that is, the higher the level of teachers, the higher the level of school running. In other words, the level of teachers is the main factor affecting the school running level.

The interaction between student factor $\mathrm{x} 1$ and conditional factor $\mathrm{x} 3$ has a significant impact on the overall school running level of schools. As far as Chinese undergraduate universities are concerned, on the one hand, the realization of the talent cultivation function (students' growth) provides the schools with financial support such as government input, students' payment and social donation, and the investment of funds into the field of material elements, which constitutes the basic conditions for running a school. On the other hand, the students' factor is the inherent requirement of teaching 
quality. Su, good school-running conditions are the basis for improving the level and quality of teaching, the two complement each other, will inevitably have a positive impact on the level of school-running.

The interaction between management elements $\mathrm{x} 4$ and cultural elements $\mathrm{x} 5$ has a significant impact on school running level. For China's undergraduate universities, on the one hand, school ethos (the main content of campus culture) as a universally accepted way of thinking, value judgment and behavior habits have an important impact on the management of managers, that is, school ethos is the constraints of management elements; on the other hand, school management is the guarantee of school efficiency, Campus Culture imperceptibly plays the role of teaching and educating people. The two complement each other and will inevitably have a positive impact on the level of school running.

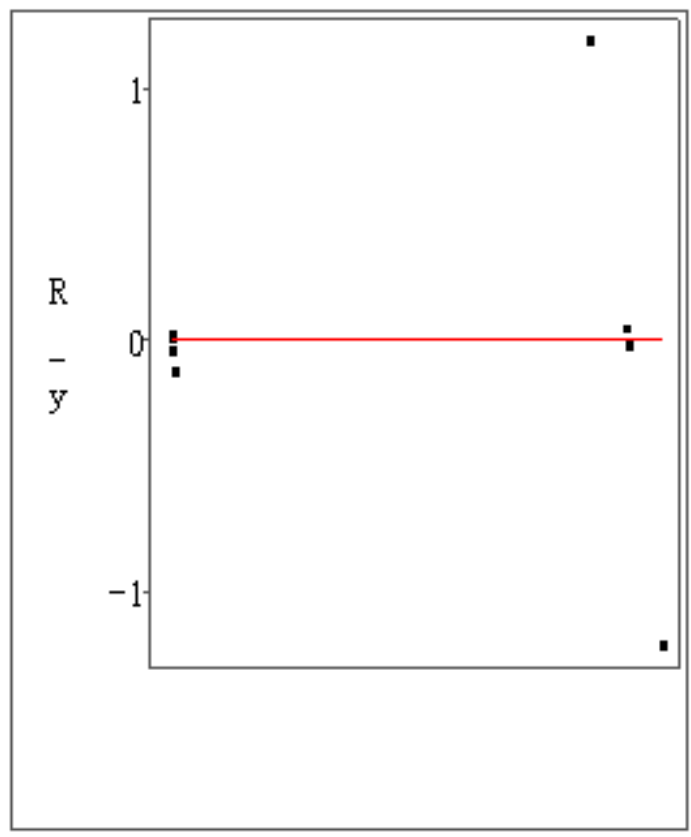

Fig. 2. Model verification

\section{Acknowledgement}

This research were financially supported by Heilongjiang Social Science Foundation (Grant No. 17SHD204).

\section{References}

[1] Z. P. Li, W. D. Wu: China Higher Education Research vol. 6 (2005), pp. 39

[2] Z. P. Li, W. D. Wu: China Higher Education Research vol. 7 (2006), pp. 56

[3] Z. P. Li, H. B. Zhang and et al: Heilongjiang Researches on Higher Education vol. 10 (2006), pp. 77

[4] Z. P. Li: Heilongjiang Researches on Higher Education vol. 3 (2005), pp. 22

[5] Z. P. Li: Education Exploration vol. 4 (2005), pp. 38

[6] Z. P. Li and et al: Journal of Harbin University vol. 10 (2005), pp. 64 